\title{
Cardiac Surgery in Octogenarians and Beyond: Single Center Experience
}

\author{
Reda E. Al-Refaie ${ }^{1 *}$, Hashem Aliter ${ }^{1}$, Ricardo Gallo ${ }^{1}$, Ali Youssef ${ }^{2}$, Mushabab Al-Murayeh ${ }^{2}$, \\ Edwin Ravikumar ${ }^{2}$
}

${ }^{1}$ Department of Cardiothoracic Surgery, Mansoura University Hospitals, Mansoura, Egypt; ${ }^{2}$ Department of Cardiac Surgery and Cardiology, Armed Forces Hospitals Southern Region, Khamis Mushayt, KSA.

Email: *reda_hammad2000@yahoo.com

Received March $16^{\text {th }}, 2013$; revised April 30 ${ }^{\text {th }}, 2013$; accepted May $7^{\text {th }}, 2013$

Copyright @ 2013 Reda E. Al-Refaie et al. This is an open access article distributed under the Creative Commons Attribution License, which permits unrestricted use, distribution, and reproduction in any medium, provided the original work is properly cited.

\begin{abstract}
Background: Increasing numbers of octogenarians and improvements in surgical techniques and postoperative care have resulted in increasing cardiac operations in this age. The aim is to analyze our experience of cardiac surgery on octogenarians and beyond concerning postoperative morbidities and mortality. Methods: 67 octogenarians and nonagenarians underwent open heart surgery in our hospital between 2001 to 2009 were retrospectively reviewed. Data included baseline preoperative status, intraoperative and perioperative course, and immediate outcomes. Results: The mean age was $86.22 \pm 6.1$ years. $86.6 \%$ patients were males. Symptoms were dyspnea; Class II in $13.4 \%$, Class III in $55.2 \%$, Class IV in $31.4 \%$ patients; angina in $82.1 \%$, and CHF in $25.4 \%$ patients. The mean EF was $37.8 \% \pm 10$. Risk factors include smoking in $52.2 \%$, DM in $37.3 \%$, hypertension in $28.4 \%$, obesity in $25.4 \%$, previous $\mathrm{MI}$ in $22.4 \%$, COPD in $17.9 \%$, renal insufficiency in $11.9 \%$, pulmonary hypertension in $7.5 \%$, PVD in $6 \%$, and cerebrovascular disease in $3 \%$ patients. The procedures were isolated CABG in 73\%, AVR in 9\%, MVR in 6\%, CABG/valve in 9\%, and MVR and AVR in 3\% patients. Complications were $18 \%$. It included renal impairment in $18 \%$, arrhythmias in $14.9 \%$, bleeding in $6 \%$, prolonged ventilation in $13.4 \%$, CHF in $4.5 \%$, gastrointestinal bleeding in $4.5 \%$, wound infection in $7.5 \%$, and cerebrovascular accident in $3 \%$. Hospital mortality was $9 \%$ patients. Conclusions: Cardiac surgery can be performed safely with acceptable hospital morbidity and mortality in octogenarians and beyond. Early referral and proper selection of patients are mandatory to improve immediate postoperative survival.
\end{abstract}

Keywords: Coronary Artery Bypass Graft; Valve; Octogenarians; Nonagenarian

\section{Introduction}

The elderly are a challenging group of patients undergoing surgical procedures. Their functional reserve capacity is diminished compared with younger patients [1], and elderly patients are more likely to have preoperative comorbid conditions [2]. Approximately $40 \%$ of all octogenarians and beyond have symptomatic cardiovascular disease, including $18 \%$ with ischemic heart disease [3]. Despite maximum medical therapy, many patients older than 80 years of age are severely symptomatic with cardiovascular disease [4].

Advances in cardiopulmonary bypass technique, myocardial protection, and improved perioperative care have allowed coronary artery bypass grafting and valve replacement operations to be safely offered to patients older than 80 years of age $[1,4,5]$. Octogenarians with signifi-

"Corresponding author. cant symptoms of cardiovascular disease frequently are referred for operation to try to improve their quality of life. Recent studies have shown that cardiac surgical procedures performed in elderly patients, in otherwise good physical and mental health, can improve mortality, morbidity, and quality of life of those patients. However, results are still incomplete, especially for valve procedures [4-6]. Careful follow up of these patients is required to continually reevaluate the benefit obtained given the increased cost of delivering health care [4].

The purpose of this study was to analyze our local experience of cardiac surgery on octogenarians and beyond in our tertiary care referral center concerning postoperative morbidities and mortality.

\section{Patients and Methods}

From June 2001 to June 2009 at the Department of Car- 
diac Services, King Fahad Military Hospital, 67 patients aged 80 years or older who underwent open cardiac surgery were retrospectively reviewed. The selected patients for surgery were previously functional until the recent diagnosis of cardiac disease, had a perceived reduction in their quality of life, were on maximal medical therapy, were not candidates for percutaneous coronary intervention, or could not be discharged from hospital because of life-threatening cardiac lesion, such as severe left main disease or critical aortic stenosis. Patients excluded from surgery were generally deemed too high risk because of severe comorbid conditions. All demographic, clinical, laboratory, surgical, and survival data were obtained from the chart.

Operative data were included type of the surgical procedure, bypass and cross-clamp times, type of the valve used, and mean arterial pressure during bypass. The preoperative and postoperative course was followed up for the occurrence of complications or death, transfusion requirements, use of inotropes and vasopressors, length of stay, and discharge plans.

Surgical techniques included a standard median sternotomy after induction and maintenance of general anesthesia. We used internal mammary artery and great saphenous vein as a conduit with variable indications. The cardiopulmonary bypass was established with mild systemic hypothermia $\left(32^{\circ} \mathrm{C}\right)$. Myocardial protection was achieved using antegrade and retrograde warm or cold blood cardioplegia. Construction of the distal anastomoses was performed first, followed by valve procedure in cases of combined procedure, and the proximal anastomoses were performed after closing the cardiac chambers and de-airing. We used a single clamp technique for the proximal anastomosis. Pharmacological or mechaniccal support was provided to the patient as required. All patients were admitted to the intensive care unit postoperatively.

\section{Statistical Analyses}

All data was transferred to SPSS version 16. Continuous variables were expressed as mean \pm standard deviation (SD) and categorical variables are reported as percentages. The unpaired $t$ test and $\mathrm{X}$ or Fisher's exact test for continuous and categorical data respectively. Statistical significance was defined by a P value less than 0.05 .

\section{Results}

Of the 67 patients studied, 58 (86.6\%) patients were males; the mean age was $86.22 \pm 6.1$ years (ranging from 80 to 102). The clinical characteristics of these patients are listed in Table 1. The most common presenting symptoms were dyspnea in all patients; 37 (55.2\%) of them were NYHA Class III, 21 (31.4\%) were in Class IV,
Table 1. Clinical characteristics of patients.

\begin{tabular}{|c|c|c|}
\hline Variable & No. of Patients & P Value \\
\hline Age (mean \pm SD) & $86.22 \pm 6.1$ & \\
\hline Range & 80 to 102 & \\
\hline Sex (male/female) & $58(86.6 \%) / 9(13.4)$ & $<0.001$ \\
\hline \multicolumn{3}{|l|}{ NYHA classification } \\
\hline II & $9(13.4 \%)$ & \\
\hline III & $37(55.2 \%)$ & $<0.001$ \\
\hline IV & $21(31.4 \%)$ & \\
\hline LVEF & $37.8+10$ & \\
\hline Angina & $55(82.1 \%)$ & $<0.001$ \\
\hline CHF & $17(25.4 \%)$ & $<0.001$ \\
\hline \multicolumn{3}{|l|}{$\mathrm{C} \mathrm{V}$ and general risk factors } \\
\hline Tobacco use & $35(52.2 \%)$ & $>0.05$ \\
\hline DM & $25(37.3 \%)$ & $<0.05$ \\
\hline HTN & $19(28.4 \%)$ & $<0.001$ \\
\hline Obesity & $17(25.4 \%)$ & $<0.001$ \\
\hline PVD & $4(6 \%)$ & $<0.001$ \\
\hline CVD & $2(3 \%)$ & $<0.001$ \\
\hline MI & $15(22.4 \%)$ & $<0.001$ \\
\hline COPD & $12(17.9 \%)$ & $<0.001$ \\
\hline Renal insufficiency & $8(11.9 \%)$ & $<0.001$ \\
\hline Pulmonary hypertension & $5(7.5 \%)$ & $<0.001$ \\
\hline Inotropic support & $5(7.5 \%)$ & $<0.001$ \\
\hline IABP & $2(3 \%)$ & $<0.001$ \\
\hline Mechanical ventilation & $2(3 \%)$ & $<0.001$ \\
\hline
\end{tabular}

$\mathrm{P}>0.05=$ non-significant; $\mathrm{P}<0.05=$ significant $\mathrm{P}<0.001=$ highly significant. Congestive Heart Failure (CHF), Cardiovascular (CV), Diabetes Mellitus (DM), Systemic Hypertension (HTN), Peripheral Vascular Disease (PVD), Cerebrovascular Disease (CVD), Preoperative Myocardial Infarction (MI), Chronic Obstructive Pulmonary Disease (COPD), Intra-Aortic Balloon Pump (IABP).

and the rest 9 (13.4\%) patients were in Class II, angina in $55(82.1 \%)$ patients, and congestive heart failure in 17 (25.4\%) patients. The mean left ventricular function was $37.8 \% \pm 10$.

The commonly reported preoperative cardiovascular and general risk factors include tobacco use in 35 (52.2\%) patients, diabetes mellitus in 25 (37.3\%) patients, systemic hypertension in 19 (28.4\%) patients, obesity in 17 (25.4\%), previous myocardial infarction in 15 (22.4\%) patients, chronic bronchopulmonary disease in 12 (17.9\%) patients, renal insufficiency in $8(11.9 \%)$ patients, pulmonary hypertension in 5 (7.5\%), peripheral vascular disease in 4 (6\%) patients, and cerebrovascular disease in 2 (3\%) patients. Preoperatively there were 5 (7.5\%) patients on inotropic support and 2 (3\%) patients ventilated and on the intraortic aortic balloon pump.

Although the majority of patients were subjected to 
coronary artery bypass grafting (CABG) other operations such as mitral valve replacement (MVR), or aortic valve replacement (AVR), or both were performed in a considerable proportion of cases. Details of operative procedures are presented in Table 2. The surgical procedures were CABG alone in 49 (73\%) patients (mean of 3.4 grafts per patient; ranging from 1 - 5 grafts) one of them required left ventricle aneurysm repair, AVR in 6 (9\%) patients, MVR in 4 (6\%) patients; one of them required left atrial clot removal, CABG/valve procedures was done in 6 (9\%), and MVR and AVR in 2 (3\%) cases.

Operative management included the use of cardio 49 of CABG procedures were performed off pump. Thirteen patients were operated upon on emergency bases; consisting of 9 CABG, one AVR, and 3 patients CABG/ AVR. The mean cardiopulmonary bypass and crossclamp times were $96.1 \pm 19.3$ minutes and $81.6 \pm 17.8$ minutes, respectively. All valves used were bioprosthetic valves. The mean arterial blood pressure was maintained at $70 \pm 15 \mathrm{~mm} \mathrm{Hg}$ during CPB.

All patients required blood transfusion perioperatively (a mean of $5.7 \pm 4 \mathrm{U}$ of packed red blood cells). Thirty seven (55.2\%) required both fresh frozen plasma and platelets for perioperative bleeding. Fifty-five patients (82.1\%) required inotropic or vasopressor support during their perioperative course.

Postoperative complications are listed in Table 3. Twelve (18\%) patients developed postoperative complication. The most common complication was renal impairment in 12 (18\%) patients followed by arrhythmias mainly atrial fibrillation in 10 (14.9\%) patients. 4 (6\%) patients developed postoperative bleeding that required

Table 2. Operative details.

\begin{tabular}{lcc}
\hline \multicolumn{1}{c}{ Variable } & No (\%) & P Value \\
\hline Procedure & $49(73 \%)$ & \\
CABG & $3(4.5 \%)$ & \\
CABG + AVR & $3(4.5 \%)$ & $<0.001$ \\
CABG + MVR & $6(9 \%)$ & \\
AVR & $4(6 \%)$ & \\
MVR & $2(3 \%)$ & \\
DVR & & \\
Timing of surgery & $54(80.6 \%)$ & $<0.001$ \\
Elective & $13(19.4 \%)$ & \\
Emergency & $96.1 \pm 19.3$ & $<0.001$ \\
CPB time (min) & $81.6 \pm 17.8$ & $<0.001$ \\
Aortic cross clamp time (min) & 3.4 (from 1 to 5$)$ & \\
No of grafts per patient & $20(100 \%)$ & \\
Bioprostheses &
\end{tabular}

$\mathrm{P}>0.05$ = non-significant; $\mathrm{P}<0.05=$ significant; $\mathrm{P}<0.001=$ highly significant. Coronary Artery Bypass Graft (CABG), Aortic Valve Replacement (AVR), Mitral Valve Replacement (MVR), Double Valve Replacement (DVR), Cardiopulmonary Bypass (CPB).
Table 3. Postoperative morbidity and mortality.

\begin{tabular}{lcc}
\hline \multicolumn{1}{c}{ Complications } & No. (\%) & P Value \\
\hline Complications & $12(18 \%)$ & \\
Renal failure & $12(18 \%)$ & $<0.001$ \\
Supra ventricular arrhythmia & $10(14.9 \%)$ & $<0.001$ \\
prolonged mechanical ventilation & $9(13.4 \%)$ & $<0.001$ \\
Infection & $5(7.5 \%)$ & $<0.001$ \\
Re-exploration for bleeding & $4(6 \%)$ & $<0.001$ \\
Congestive heart failure & $3(4.5 \%)$ & $<0.001$ \\
Gastrointestinal bleeding & $3(4.5 \%)$ & $<0.001$ \\
Cerebrovascular accidents & $2(3 \%)$ & $<0.001$ \\
Tracheostomy & $2(3 \%)$ & $<0.001$ \\
Cause of death (6 patients) & $6(9 \%)$ & \\
Myocardial infarction & $2(3 \%)$ & \\
Respiratory failure & $2(3 \%)$ & \\
Sepsis and multi-organ failure & $2(3 \%)$ & \\
\hline
\end{tabular}

$\mathrm{P}>0.05=$ non-significant; $\mathrm{P}<0.05=$ significant $\mathrm{P}<0.001=$ highly significant.

exploration. Among the 9 (13.4\%) patients required prolonged mechanical ventilation (more than 24 hours), 3 patients developed pneumonia. Other complications included congestive heart failure in $3(4.5 \%)$ patients, gastrointestinal bleeding in 3 (4.5\%) patients, wound infection in 5 (7.5\%), cerebrovascular accident in 2 (3\%) patients, and tracheostomy in 2 (3\%) patients. Mean intensive care unit length of stay of surviving patients was 6.8 \pm 4 days, and the mean overall hospital stay was $18 \pm 11$ days.

Hospital mortality occurred in 6 (9\%) patients. Of these 6 patients, five had CABG, and one had combined AVR and CABG. Four patients were operated upon urgently. Causes of death were respiratory insufficiency in 2 patients; both of them were mechanically ventilated preoperatively and on intraaortic balloon and inotropic support, myocardial infarction in 2 patients, and sepsis and multi-organ failure in 2 patients (Table 3).

\section{Discussion}

The increasing age of patients is a distinctive feature of the current cardiac surgical practice. The elderly are now the fastest growing population in Western countries, and the number of elderly patients with disease potentially eligible for surgery is expected to increase [7-9]. This entails a complex decision-making process that involves ethical, social, and economic issues. Additionally, escalating medical costs impose a cost-effective medical care. Indeed, this represents a true challenge in elderly patients, who are more likely to have morbid conditions and a prolonged and complicated postoperative course [10]. Uncertainties also exist regarding the impact of surgery on 
the long-term prognosis [9].

This study represents our local experience in a tertiary care referral center of Saudi octogenarians and beyond undergoing cardiac surgery, either CABG, combined CABG and valve surgery, or isolated valve surgery. The number of operations performed for octogenarians have progressively increased in our center. In the general population, the life expectancy for women is significantly longer than that for men. However, we reported a higher proportion of male patients requiring cardiac surgery. Similar increases in cardiac surgical procedures involving the very elderly men have been reported by other groups [9-12].

The prevalence of coronary artery disease increases with age. The association of valvular heart disease and coronary artery disease is a common finding in elderly patients [13]. In our study, we reported the prevalence of coronary artery disease in octogenarians and beyond where $73 \%$ of our patients required isolated CABG and $9 \%$ of patients required aortic or mitral valve replacement in combination with CABG for surgical treatment of coronary artery disease. In addition, valve replacement was encountered in $18 \%$ patients. These results correlate with other reports [4,9,12-14].

As it has been generally observed in prior reports of CABG in octogenarians, most patients in this age group present with New York Heart Association functional Class III or IV symptoms that are always refractory to more conservative management [4-6,12]. In our study, $55.2 \%$ of the patients were in Class III and 31.4\% were in Class IV. Other symptoms included anginal pain in (82.1\%) patients and congestive heart failure signs and symptoms in $25.4 \%$ of patients. These results match with other reports [4-6, 12,15].

Elderly patients tend to have a lack of functional reserves and an increased presence of chronic medical diseases. These patients also tend to have a higher NYHA class and a higher surgical priority than patients younger than 80 years of age. These findings suggest that patients 80 years of age or older referred for cardiac operation seem to have more advanced ischemic disease when compared with younger patients [16]. The preoperative patient characteristics in our population of octogenarians were similar to those listed in other publications [4,16-18].

In all our valve procedures in octogenarians and beyond we used the bioprosthetic valves. The policy of using biologic valves in octogenarians, if possible would seem beneficial because it obviates lifelong anticoagulation with warfarin $[12,19]$. Bioprosthetic valves may be much more durable in the elderly than in younger populations. In the octogenarian, the durability of the bioprosthetic valve clearly exceeds expected survival. When valve replacement is indicated and anticoagulation can be avoided, a bioprosthetic valve appears to be the best choice, pro- vided a suitable size can be implanted [12,19-21].

Our postoperative complication rate was $17.9 \%$ of patients. The most common complication was renal impairment $17.9 \%$ patients followed by arrhythmias in $14.9 \%$ patients. Other complications included postoperative bleeding, prolonged mechanical ventilation, congestive heart failure, gastrointestinal bleeding, cerebrovascular accident, and wound infection. The incidences and nature of postoperative complications in our study are comparable to other reports $[4,6,9,14,15]$. It has been previously reported that octogenarians tend to have a longer postoperative length of stay than younger patients [4]. In this report, the mean intensive care unit length of stay of surviving patients was $6.8 \pm 4$ day, and the mean overall hospital stay was $18 \pm 11$ days. Other authors reported that this category of patients tends to stay longer in the intensive care and in the hospital $[4,6,15]$.

The increased mortality associated with coronary bypass in elderly patients compared with younger patients has a multifactorial basis and is probably not solely a reflection of the aging process [15]. Independent predictors of mortality after cardiac operations among nonagenarians are beginning to be elucidated [14]. Williams and colleagues in their multivariate analysis suggested that five risk factors including preoperative renal dysfunction, postoperative renal dysfunction, pulmonary insufficiency, intraaortic balloon pump support, and sternal wound infection are independent predictors of increased hospital mortality in octogenarians [15]. Other reports of CABG in octogenarians have documented the urgency of operation, compromised left ventricular function, peripheral vascular disease or cerebrovascular disease, and mitral insufficiency and intraaortic balloon pumping as predictors of increased mortality $[5,14,15,17,22]$. The hospital or 30 day mortality in our study occurred in $6(9 \%)$ of patients. It was cardiac related and associated comorbid conditions which was similar to those reported by others $[5,14,15$, 17,22]. All our mortalities had preoperative EF less than $30 \%$, renal impairment and chronic pulmonary disease and their renal and respiratory conditions further deteriorated after surgery. Four out of 6 patients were operated upon urgently. Causes of death were respiratory failure in 2 patients; both of them were mechanically ventilated preoperatively and on intra-aortic balloon and inotropic support, myocardial infarction in 2 patients; they required intra-aortic balloon and high inotropic support, and sepsis and multi-organ failure in 2 patients.

\section{Conclusion}

Cardiac surgery can be performed safely with acceptable hospital morbidity and mortality in octogenarians and beyond. Early referral and proper selection of patients are mandatory to improve immediate postoperative survival. 


\section{Acknowledgements}

The authors would like to thank all the staff of the cardiovascular services department at Armed Forces Hospitals Southern Region for their assistance and support in conducting this research.

\section{REFERENCES}

[1] D. D. Glower, T. D. Christopher, C. A. Milano, W. D. White, L. R. Smith, R. H. Jones and D. C. Sabiston, "Performance Status and Outcome after Coronary Artery Bypass Grafting in Persons Aged 80 to 93 Years,” American Journal of Cardiology, Vol. 70, No. 6, 1992, pp. 567-571. doi:10.1016/0002-9149(92)90192-2

[2] P. Kumar, K. J. Zehr, A. Chang, D. E. Cameron and W. A. Baumgertner, "Quality of Life in Octogenarians after Open Heart Surgery,” Chest, Vol. 108, No. 4, 1995, pp. 919-926. doi:10.1378/chest.108.4.919

[3] National Center for Health Statistics, "United States Life Tables: US Decennial Life Tables for 1979-1981, Vol. 1, No. 1,” Government Printing Office, Washington DC, 1985.

[4] D. S. Fruitman, C. E. MacDougall and D. B. Ross, "Cardiac Surgery in Octogenarians: Can Elderly Patients Benefit? Quality of Life after Cardiac Surgery,” American Journal of Cardiology, Vol. 68, No. 6, 1999, pp. 21292135. doi:10.1016/S0003-4975(99)00818-8

[5] T. P. Tsai, S. Nessim, R. M. Kass, A. Chaux, R. J. Gray, S. S. Khan, C. Blanche, C. Utley and J. M. Matloff, "Morbidity and Mortality after Coronary Artery Bypass in Octogenarians," The Annals of Thoracic Surgery, Vol. 51, No. 6, 1991, pp. 983-986. doi:10.1016/0003-4975(91)91024-P

[6] P. Kolh, A. Kerzmann, L. Lahaye, P. Gerard and R. Limet, "Cardiac Surgery in Octogenarians: Perioperative Outc ome and Long-Term Results," European Heart Journal, Vol. 22, No. 14, 2001, pp. 1235-1243. doi:10.1053/euhj.2000.2443

[7] US Bureau of the Census, "Statistical Abstract of the United States," US Government Printing Office, Washington DC, 1990.

[8] S. Greengross, E. Murphy, L. Quam, P. Rochon and R. Smith, "Aging: A Subject That Must Be at the Top of the World Agendas,” BMJ, Vol. 315, 1997, pp. 1029-1030. doi:10.1136/bmj.315.7115.1029

[9] G. Speziale, G. Nasso, M. C. Barattoni, G. Esposito, G. Popoff, V. Argano, E. Greco, M. Scorcin, C. Zussa, D. Cristell, R. Coppola, S. Chierchia, A. Marchese, P. Caldarola, K. Fattouch and L. Tavazzi, "Short-Term and Long-Term Results of Cardiac Surgery in Elderly and Very Elderly Patients," The Journal of Thoracic and Cardiovascular Surgery, Vol. 141, No. 3, 2011, pp. 725-731. doi:10.1016/j.jtcvs.2010.05.010

[10] D. S. Likosky, L. J. Dacey, Y. R. Baribeau, B. J. Leavitt, R. Clough, R. P. Cochran, R. Quinn, D. A. Sisto, D. C. Charlesworth, D. J. Malenka, T. A. MacKenzie, E. M. Olmstead, C. S. Ross and G. T. O’Connor (Northern New England Cardiovascular Disease Study Group), "Long-Term Survival of the Very Elderly Undergoing Coronary Artery
Bypass Grafting,” The Annals of Thoracic Surgery, Vol. 85, No. 4, 2008, pp. 1233-1238. doi:10.1016/j.athoracsur.2007.12.066

[11] J. S. Rumsfeld, D. J. Magid, M. O’Brien, M. McCarthy Jr., S. MaWhinney, Scd, A. L. Shroyer, T. E. Moritz, W. G. Henderson, G. K. Sethi, F. L. Grover and K. E. Hammermeister, "Department of Veterans Affairs Cooperative Study in Health Services: Processes, Structures, and Outcomes of Care in Cardiac Surgery. Changes in Health Related Quality of Life Following Coronary Artery Bypass Graft Surgery,” The Annals of Thoracic Surgery, Vol. 72, No. 6, 2001, pp. 2026-2032. doi:10.1016/S0003-4975(01)03213-1

[12] T. P. Tsai, A. Chaux, J. M. Matloff, R. M. Kass, R. J. Gray, M. A. De Robertis and S. S. Khan, "Ten-Year Experience of Cardiac Surgery in Patients Aged 80 Years and Over,” The Annals of Thoracic Surgery, Vol. 58, No. 2, 1994, pp. 445-451. doi:10.1016/0003-4975(94)92225-X

[13] D. B. Loran and J. B. Zwischenberger, "Thoracic Surgery in Elderly,” Journal of the American College of Surgeons, Vol. 199, No. 5, 2004, pp. 773-784. doi:10.1016/j.jamcollsurg.2004.08.008

[14] B. W. Ullery, J. C. Peterson, F. Milla, M. T. Wells, W. Briggs, L. N. Girardi, W. Ko, A. J. Tortolani, O. W. Isom and K. H. Krieger, "Cardiac Surgery in Select Nonagenarians: Should We or Shouldn't We?” The Annals of Thoracic Surgery, Vol. 85, No. 3, 2008, pp. 854-860. doi:10.1016/j.athoracsur.2007.10.074

[15] D. B. Williams, R. G. Carrillo, E. A. Traad, C. H. Wyatt, R. Grahowksi, H. Wittels and G. Ebra, "Determinasts of Operative Mortality in Octogenarians Undergoing Coronary Bypass," The Annals of Thoracic Surgery, Vol. 60, No. 4, 1995, pp. 1038-1043. doi:10.1016/0003-4975(95)00430-S

[16] M. S. Adkins, D. Amalfitano, N. A. Harnum, G. W. Laub and L. B. McGrath, "Efficacy of Combined Coronary Revascularization and Valve Procedures in Octogenarians," Chest, Vol. 108, No. 4, 1995, pp. 927-931. doi:10.1378/chest.108.4.927

[17] W. Ko, K. H. Krieger, W. D. Lazenby, Y. T. Shin, M. Goldstein, R. Lazzaro and O. W. Isom, "Isolated Coronary Artery Bypass Grafting in One Hundred Consecutive Octogenarian Patients. A Multivariate Analysis," The Journal of Thoracic and Cardiovascular Surgery, Vol. 102, No. 4, 1991, pp. 532-538.

[18] P. A. Kurlansky, D. B. Williams, E. A. Traad, M. Zucker and G. Ebra, "Eighteen-Year Follow-Up Demonstrates Prolonged Survival and Enhanced Quality of Life for Octogenarians after Coronary Artery Bypass Grafting," Journal of Thoracic and Cardiovascular Surgery, Vol. 141, No. 2, 2011, pp. 394-399. doi:10.1016/j.jtcvs.2010.05.003

[19] B. Chiappini, N. Camurri, A. Loforte, L. Di Marco, R. Di Bartolomeo and G. Marinelli, "Outcome after Aortic Valve Replacement in Octogenarians," The Annals of Thoracic Surgery, Vol. 78, No. 1, 2004, pp. 85-89. doi:10.1016/j.athoracsur.2003.12.060

[20] A. M. Borkon, L. M. Soule, K. L. Baughman, W. A. Baumgartner, T. J. Gardner, L. Watkins, V. L. Gott, K. A. 
Hall and B. A. Reitz, "Aortic Valve Selection in the Elderly Patient," The Annals of Thoracic Surgery, Vol. 46, No. 3, 1988, pp. 270-277. doi:10.1016/S0003-4975(10)65924-3

[21] W. R. Jamieson, L. H. Burr, A. I. Munro, R. T. Miyagishima and A. N. Gerein, "Cardiac Valve Performance in the Elderly: Clinical Performance of Biological Prostheses,” The Annals of Thoracic Surgery, Vol. 48, No. 2, 1989, pp.
173-185.

doi:10.1016/0003-4975(89)90064-7

[22] C. R. Bridges, F. H. Edwards, E. D. Peterson, L. P. Coombs and T. B. Ferguson, "Cardiac Surgery in Nonagenarians and Centenarians," Journal of the American College of Surgeons, Vol. 197, No. 3, 2003, pp. 347-356. doi:10.1016/S1072-7515(03)00384-3 